\title{
Do young children preferentially trust gossip or firsthand observation in choosing a collaborative partner?
}

\author{
Lou Haux | Jan M. Engelmann | Esther Herrmann | \\ Michael Tomasello
}

Department of Developmental and Comparative Psychology, Max Planck Institute for Evolutionary Anthropology, Leipzig 04103, Germany

\section{Correspondence}

Lou Marie Haux, Max Planck Institute for Evolutionary Anthropology, Deutscher Platz 6, 04103 Leipzig, Germany. Email: lou_haux@eva.mpg.de

\begin{abstract}
From early on in ontogeny, young children hear things being said about particular individuals. Here we investigate the ways in which testimony with social content, that is, gossip, influences children's decision-making. We explored whether five-year-old $(N=72)$ and seven-year-old $(N=72)$ children trust gossip or firsthand observation in a partner choice setting. Seven-year-old children preferentially trusted what they had seen firsthand over gossip; five-year-old children, in contrast, did not differentiate between these two sources of information. However, five-year-old children (but not seven-yearolds) generally gave negative information more weight, that is, they showed a "negativity bias." These results suggest that at around school age, young children become more "epistemically vigilant" about gossip.
\end{abstract}

\section{KEYWORDS}

decision-making, social behavior, social cognition, social learning

\section{1 | INTRODUCTION}

Much of what children learn about the world comes, in one way or another, from the testimony of others (e.g., Harris, 2012; Jaswal, 2010). Blind faith in such testimony can in many cases be harmful, and so over time, children must become discerning. Previous research has shown that preschool children already possess complex heuristics for assessing the credibility of particular informants (e.g., Corriveau, Fusaro, \& Harris, 2009; Corriveau \& Harris, 2009; Harris, 2012; Koenig, Clément, \& Harris, 2004).

Studies of children's reliance on testimony have mainly focused on the sharing of information about physical objects (e.g., Corriveau \& Harris, 2010; Harris, 2012; Jaswal, 2010). One major approach has been to study children's learning labels for unfamiliar objects. Pasquini, Corriveau, Koenig, and Harris (2007; see also Koenig et al., 2004) introduced preschoolers to two informants who labeled familiar objects with varying accuracy. In a second step, the two informants provided conflicting labels for unfamiliar objects. The authors found that preschoolers took the informants' previous behavior into consideration and selectively trusted informants who had been accurate in the past. 
Using similar approaches, researchers have revealed that children trust the majority rather than the minority (Corriveau et al., 2009), prefer information from familiar as compared to unfamiliar informants (Corriveau \& Harris, 2009), are sensitive to the accuracy of informants (Pasquini et al., 2007; see also Koenig et al., 2004), and prefer the testimony of a benevolent rather than a malevolent communicator (Mascaro \& Sperber, 2009).

Undoubtedly, testimony about the physical world plays a crucial part in children's development. However, this is not the only type of information to which children are exposed. Children receive information about social agents and their behavior, so-called gossip, from adults and peers (Baumeister, Zhang, \& Vohs, 2004; Dunbar, 2004; Engelmann, Herrmann, \& Tomasello, 2016). Gossip can be defined as evaluative testimony about social agents (Dunbar, 2004; Feinberg, Willer, Stellar, \& Keltner, 2012; Ingram, 2014). Gaining reliable information about social agents and their reputations through gossip represents a further important challenge for children from a young age onward (Herrmann, Keupp, Hare, Vaish, \& Tomasello, 2013). Children start to engage in gossip themselves from the age of five (Engelmann et al., 2016). Importantly, gossip and tattling should be differentiated and seen as two distinct behaviors. Tattling is most commonly defined as the reporting to a second party (usually an authority figure) about norm violations committed by a third party (Ingram \& Bering, 2010). Furthermore, tattling mostly occurs in situations where an adult is in a position to intervene on behalf of the tattler. Tattling thus shares some important characteristics with gossip, for example its evaluative nature, but is also different in crucial aspects. Whereas tattling generally seems to be motivated by children's desire to seek redress for harm done to them and does so through recruiting adult intervention, prosocial gossip is, at least sometimes, motivated by an agent's desire to help someone else and occurs between peers. In addition, whereas tattling mostly occurs overtly, gossip is often carried out covertly (Ingram \& Bering, 2010).

Children regularly receive information about friends and classmates that could potentially be useful; such reputational information allows individuals to selectively recruit cooperators and avoid cheaters. In addition, the fact that reputational information is spread via gossip provides a motivation for individuals themselves to cooperate and resist defecting in social dilemmas (Feinberg et al., 2012; Wedekind \& Milinski, 2000). The importance of gossip for social interaction means that individuals must also be ever vigilant about its veracity, for example, assessing the communicator's selfish interests in having the testimony be believed (Sperber et al., 2010).

Little attention has been paid to children's trust in testimony about social agents-that is, gossip (we use the two terms interchangeably)-rather than physical objects. One relevant factor in gaining information about social agents is the source of information (Nowak \& Sigmund, 2005). We often gain information about individuals directly, either by interacting with them or observing them in third-party contexts. However, such direct interactions or observations are not always available; in particular, as groups get larger, gossip about a potential partner's reputation might have to substitute for direct experience. In some cases, evidence obtained from different sources, for example observation and gossip, might reveal contradictory information. Exploring the behavior of adult participants, Sommerfeld, Krambeck, Semmann, and Milinski (2007) found that participants selectively trusted gossip information even when it conflicted with their own firsthand observation. Jaswal (2010) explored young children's selective trust in information about physical objects in similar contexts. More specifically, across four studies, Jaswal (2010) investigated whether two-anda-half-year-old children trusted more in a self-generated truth or in testimony about the trajectory of a physical object. Overall, Jaswal's findings demonstrated that young children repeatedly trusted the testimony of others about the physical world; intriguingly, this was true even in cases when testimony clearly conflicted with an event the children had just witnessed.

The aim of the present study was to investigate which information source-gossip or observation-five and sevenyear-old children selectively trust when receiving information about social agents. We focused on these age groups, because previous research had shown that from the age of five children start to engage in gossip themselves (Engelmann et al., 2016; Fine, 1977). Furthermore, we were interested in how various experiences with gossip at school influence children's trust in gossip (see also La Greca, Parker, \& Kuttler, 2002) and so we tested seven-year-old children as a second age group.

In the present study, children received information about a target individual from two different information sources: gossip and firsthand observation. Children received conflicting information from these two different sources; in 
one condition they learned something positive about the target puppet through gossip and something negative through firsthand observation, or, in a second condition, children learned something negative about the target puppet through gossip and something positive through firsthand observation. After a child was exposed to both information sources, she had to choose between the target individual and a neutral partner with whom she had no previous experience as a partner. Based on the results by Jaswal (2010) and Sommerfeld et al. (2007), we predicted that children would trust in gossip information even though this information conflicted with their own firsthand observation. Specifically, we predicted that children who trusted gossip would thus choose the target puppet in the gossip positive/direct negative condition and choose the neutral puppet in the gossip negative/direct positive condition.

\section{2 | METHOD}

\section{1 | Participants}

We tested 72 five-year-old children ( $M=64$ months; $S D=1.8$ months; $R=63-68$ months) and 72 seven-year-old children ( $M=85$ months; $S D=2.4$ months; $R=81-90$ months) in the experimental conditions. Thirty-six five-year-olds (18 girls, 18 boys) and 36 seven-year-olds (18 girls, 18 boys) participated in one trial in one of the two conditions (gossip positive/observation negative and gossip negative/observation positive). An additional 12 five-year-old children were tested but not included in the final sample because they could not answer the comprehension questions (see procedure) correctly $(n=7)$, did not want to continue the game $(n=2)$, or for technical reasons $(n=3)$. Two additional seven-year-olds were tested but not included in the final sample due to technical errors.

Each participant saw a gossip and an observation video featuring a same-sex confederate $(M=86$ months; $S D=7.1 ; R=79-97$ months; two girls and two boys). Confederates were recruited from different day-care centers than participants to ensure that they were unknown to each other.

Furthermore, an additional 24 five-year-olds $(M=65$ months; $S D=1.7$ months; $R=63-69$ months; 12 girls, 12 boys) participated in a manipulation control. The manipulation control consisted of two situations (gossip positive/direct positive and gossip negative/direct negative). This control was included in order to determine whether children paid attention to and understood the content of the videos. In the gossip positive/direct positive condition we expected children to choose the target puppet and in the gossip negative/direct negative children should choose the neutral puppet.

Children were free to choose not to participate at any time. Participants were randomly assigned to one of the two conditions and tested in a quiet room in different day care centers in a medium-sized city in Germany. All participants were native German speakers.

\subsection{Materials}

The study room contained a table with two laptops (13-inch MacBooks), one showing the observation video and the other the gossip video. There were three puppets: a striped, a spotted, and a white puppet who gossiped in the gossip video. The puppets were not referred to or introduced as either male or female. The target puppet (either striped or spotted) and the neutral puppet (either striped or spotted) sat at a small table on two separate chairs. The puppet table with the target and the neutral puppet was approximately one and a half meters in front of the laptop table. The white puppet (gossip puppet) was positioned at a different table (see Figure 1).

\section{3 | Videos}

\subsection{1 | Observation videos}

In the positive observation video, a child played the clown game (see procedure below) with the striped or the spotted puppet. The child reached for the clown head twice. The target puppet gave the clown's head to the child and left. The child remained in the picture. In the negative observation, the basic setup was unchanged but when the child reached for the clown head, the puppet destroyed the clown, took the clown's head, and left. 


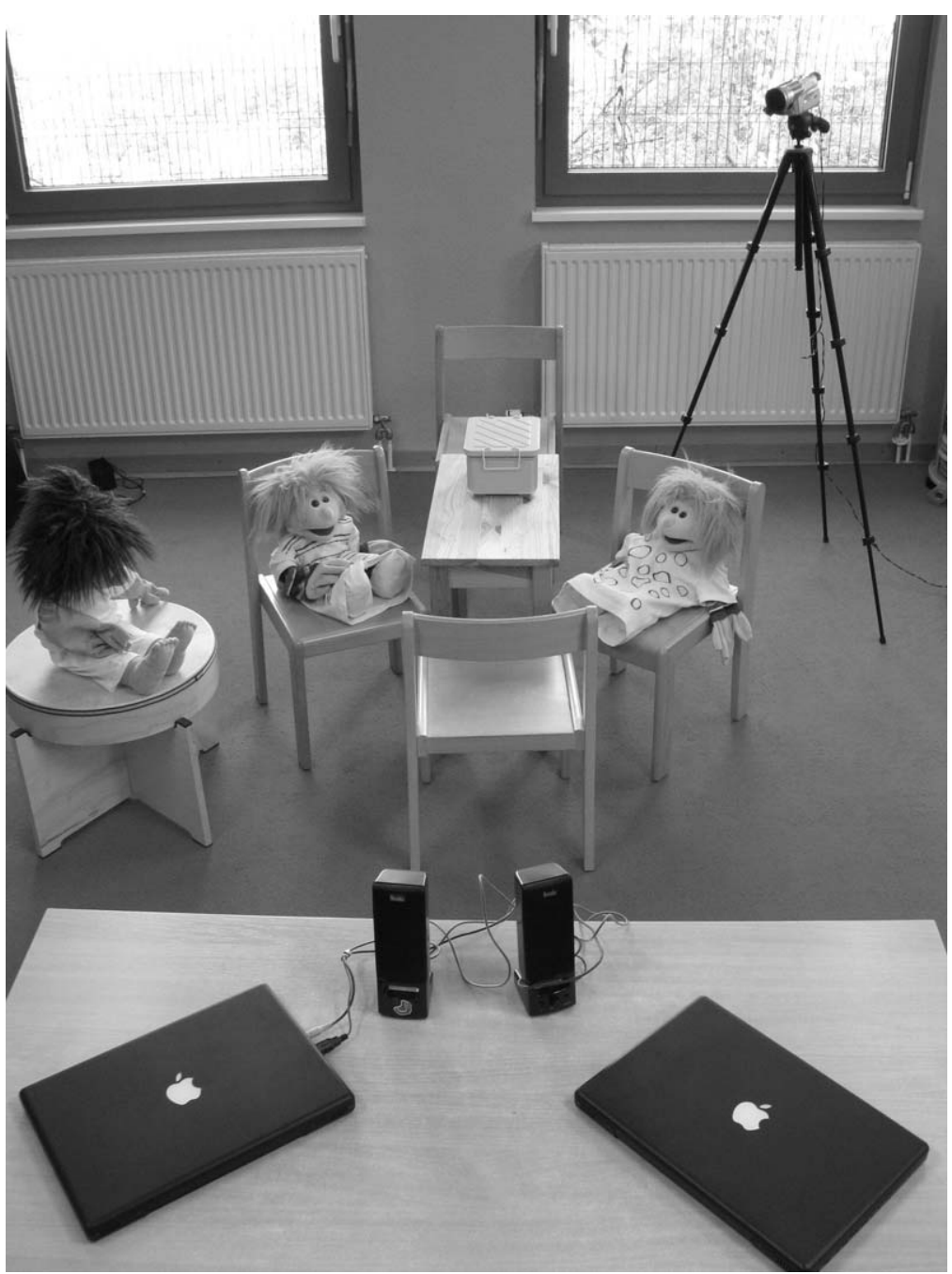

FIGURE 1 Setup of the study in a day-care center

\subsection{2 | Gossip videos}

In the positive video, the gossip puppet (white puppet) and a child confederate sat at a table. The target puppet walked from left to right and left the scene. The child and the gossip puppet followed the target puppet with their eyes. The gossip puppet said to the child: "Have you already heard? In the clown game, the spotted (or striped) puppet always helps." Child answered: "I see." In the negative gossip video, everything was the same as in the positive gossip video, but this time the white puppet said to the child: "Have you already heard? In the clown game the spotted (or striped) puppet breaks everything." Again, the child answered: "I see."

\section{4 | Procedure}

The experimenter entered the room with the participant. The child was first introduced to the clown game in which five wooden pieces, representing different parts of the clown (the feet, the legs, the hip, the chest, and the head) have to be assembled in the correct sequence. The experimenter then showed the child how to build the clown. Furthermore, the child was told that in the clown game, the head of the clown is always in the possession of the target puppet. In addition, the child received the information that there are some puppets that are helpful-that is, they help the participant to construct the clown by handing over the clown's head-and there are some puppets that are antisocial, 
that is, they do not help the participant to construct the clown but take the head away and destroy the clown game. The participant learned that to win the clown game and receive a sticker reward, the clown would have to be properly assembled. If the clown were destroyed, the child would lose the game and not receive a sticker.

In this way, the child learned that some puppets are social and others antisocial. Thereupon, the child had to decide with which puppet he or she wanted to play the clown game. The child could choose between the neutral and the target puppet. The experimenter explained to the child that before he or she could choose one of the puppets to play with, they would watch two videos to get further information about one of the two puppets (the target puppet). Children were thus always exposed to two different kinds of information sources (observation and gossip) about a single target puppet. Information sources always conflicted. In one condition, the observation video was positive and the gossip video was negative; in a second condition, the observation video was negative and the gossip video was positive. The experimenter and the child watched both the observation video and the gossip video twice. Both videos featured the same target puppet, so the child received information about only the target puppet and not the neutral puppet.

After having watched the video for the first time, the experimenter asked all participants three comprehension questions: (1) "What happened?" (for the observation video) or "What did the puppet say?" (for the gossip video) (2) "Which puppet?" (3) "What did the puppet do?" Participants were coded as having answered the three questions correctly if they appropriately described what the puppet had done (question 1 and 3); for example, they could mention that the target puppet helped to build the clown game or destroyed it (observation video). In the case of the gossip video, they could describe what the gossip puppet had said, for example mentioning that the gossiper believed that the puppet always helps to build the clown game or destroys it. In addition, children had to correctly label the puppet, for example, the spotted puppet (question 2). If the answers were correct, the experimenter said: "Mm, let's watch the video again." If the answers were wrong the experimenter said: "Mm, have a closer look at the video." The experimenter then started the video for the second time. If the child had not correctly answered the questions after the first viewing, the experimenter asked the child the same three questions as before. Children who could not answer the questions correctly were not included in the final sample.

Subsequently, after watching the videos, the experimenter asked the child: "You can now play the clown game with one of the two puppets." "Which puppet helps you to win?" While posing this question, the experimenter, using both hands, simultaneously pointed toward the spotted and striped puppet. The child could play either with the target puppet, about which he or she had received conflicting information, or with the neutral puppet.

During the manipulation checks, the procedure was identical to test trials. Participants saw the same videos as in the test phase, but now the information of the two information sources was congruent. Thus, children watched the gossip positive and the observation positive videos or the gossip negative and the observation negative videos. We did not use the manipulation checks for the seven-year-old children, as all of the five-year-old children answered according to our expectations (see results).

For all participants, we counterbalanced the order of the videos (either the gossip video or the observation video was presented first), the identity of the target puppet (either the striped or the spotted puppet was the target puppet in the video and the other puppet was the neutral puppet), and the order of the game rules (either the win situation or the lose situation was explained first). In addition, participant gender was matched to confederate gender (in the video), and two sets of videos were used (featuring different confederates) to control for individual effects. All videos had an equal length of $26 \mathrm{sec}$.

\section{$2.5 \mid$ Coding and analysis}

All trials were videotaped with one camera and coded by the first author. The child's choice of the neutral or target puppet was coded. A research assistant, unaware of the study design and hypothesis, independently coded $25 \%$ of all trials. Interrater agreement was excellent $(k=1)$.

Children were coded as relying on gossip information if they picked the target puppet in the gossip positive/observation negative condition and the neutral puppet in the gossip negative/observation positive condition. Conversely, children were coded as relying on firsthand information if they picked the target puppet in the gossip negative/ 
observation positive condition and the neutral puppet in the gossip positive/observation negative condition. In addition, in both conditions (gossip positive/observation negative and gossip negative/observation positive), children were coded as relying on negative information if they picked the neutral puppet.

\section{3 | RESULTS}

We analyzed the data using a Generalized Linear Model with binomial error structure and logit link function (McCullagh \& Nelder, 2008). Into this we included as test predictors the factors age and condition and also their interaction. As a control predictor we included gender. To establish the significance of the test predictors (Forstmeier $\&$ Schielzeth, 2011), we used a likelihood ratio test (Dobson, 2008), comparing its deviance with that of the null model comprising only gender. The response of the information source hypothesis model was whether or not children relied on gossip.

\section{1 | Preliminary results}

Results of the manipulation check showed that participants paid attention to the videos and understood their content. Specifically, $100 \%$ of children chose the target puppet in the gossip positive/observation positive situation and $100 \%$ of children chose the neutral puppet in the gossip negative/observation negative situation.

\section{2 | Main results}

Overall, the source of information was relevant for children's choice. The full model was significantly different from the null model for the information source hypothesis (likelihood ratio test: $\chi^{2}=11.6, d f=3, p=.009$ ). This means that either one, or both, or the interaction of the main effects had a significant influence on children's probability of trusting gossip.

Specifically, there was a significant interaction between age and treatment $\left(\chi^{2}=5.67, d f=1, p=.017\right)$. We thus looked at both ages separately. This analysis revealed that seven-year-olds relied on observations significantly more than five-year-olds $\left(\chi^{2}(1, N=144)=4.028, p=.045\right)$. This was also true within age group: a binomial test revealed that the number of seven-year-olds relying on firsthand observation was significantly greater than chance $(p=.044)$. For the younger children, also source of information did not have a significant influence; five-year-old children, did not differentiate between observation and gossip information (Binomial test, $p=.556$ ) (Figure 2a and $2 \mathrm{~b}$ ).

Furthermore, we found that information valence (negative or positive) was relevant for children's choice. A full/ null model comparison showed that information valence played a role in children's choices (likelihood ratio test: $\left.\chi^{2}=11.6, d f=3, p=.009\right)$. There was a significant interaction between age and treatment $\left(\chi^{2}=5.67, d f=1, p=.017\right)$. We thus looked at the two age groups separately and found that five-year-olds relied on negative information significantly more than seven-year-olds $\left(\chi^{2}(1, n=144)=7.161, p=.008\right)$. This was also true within age group: five-yearolds were significantly more likely than chance to rely on negative information (Binomial test, $p=.013$ ). Information valence did not have a significant effect for the seven-year-old children, who relied on negative and positive information equally (Binomial test, $p=.289$ ) (Figure $2 \mathrm{a}$ and $2 \mathrm{~b}$ ).

\section{DISCUSSION}

In the present study, we investigated young children's trust in testimony in a social situation using a partner choice paradigm. In particular, we investigated which information source young children selectively trust: firsthand observation or gossip. In addition, we explored whether the valence of information (positive or negative) affects young children's decision-making.

The following developmental picture emerged. Seven-year-old children's selection of a cooperative partner was influenced by the source of information. The older age group in our sample selectively relied on what they had seen with their own eyes, and were skeptical of gossip. However, the source of information did not have a significant effect 


\section{a 5-year-old children}

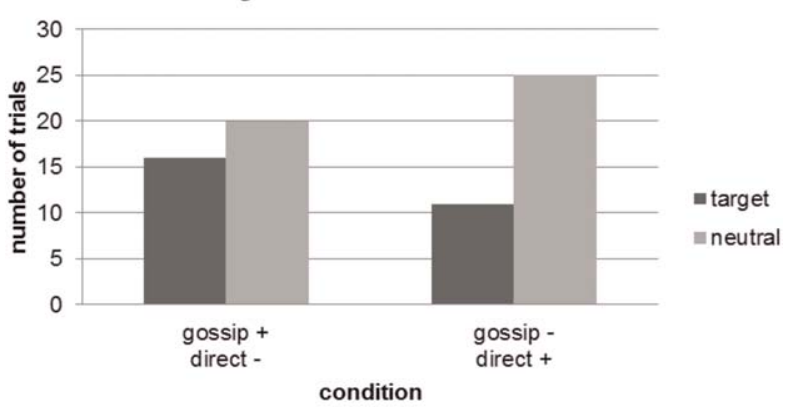

b 7-year-old children

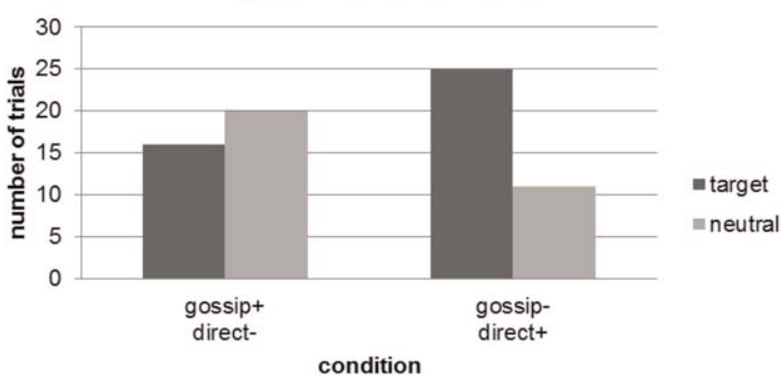

FIGURE 2 Choice of the target and neutral puppet of (a) five-year-old and (b) seven-year-old children. We coded whether five-year-old and seven-year-old children trusted gossip information or firsthand observation. Children were coded as relying on gossip information if they picked the target puppet in the gossip positive/observation negative condition and the neutral puppet in the gossip negative/observation positive condition. Conversely, children were coded as relying on firsthand information if they picked the target puppet in the gossip negative/observation positive condition and the neutral puppet in the gossip positive/observation negative condition. In addition, in both conditions (gossip positive/observation negative and gossip negative/observation positive), children were coded as relying on negative information if they picked the neutral puppet

on five-year-old children's behavior. Our post hoc analysis suggests that information valence constituted the decisive factor for five-year-old children. The younger participants selectively relied on negative, rather than positive, information. The behavior of the older age group, on the other hand, was not influenced by information valence.

This is the first study to investigate children's selective trust in information about other people. Although previous studies had found that preschoolers (Jaswal, 2010) and adults (Sommerfeld et al., 2007) trust testimony and gossip over firsthand information, we found that seven-year-old children relied on their own firsthand observation. What could account for this difference? Regarding the study by Sommerfeld and colleagues, two potential factors emerge. First, in Sommerfeld et al., participants received two pieces of information about potential partners: written gossip statements indicating the character of the potential partner and statements indicating the actual cooperative record of the same partner. In contrast to the current study, in the study by Sommerfeld and colleagues participants never directly observed the actions of the potential partner but only had access to records about past behavior. Directly observing a behavior, as in the present study, might simply be more influential than access to records. Second, adults might have an understanding of gossip that children at age seven still lack. According to Sperber and Baumard (2012), reputational gossip is not just an opinion but a widely shared judgment. Thus, adults might have evaluated gossip as more representative than a single personal observation and consequently trusted the former more, whereas children at age seven might not yet be aware of the collective nature of reputational gossip.

As for the discrepancy between the results of Jaswal (2010) and the present study, a main difference lies in the fact that Jaswal's study took place in a physical context-the information concerned a non-social agent-and our study in a social context, that is, information concerned a social agent. Children might be more skeptical of testimony in social 
compared to physical contexts. However, it is unclear why the five-year-old children did not differentiate between firsthand versus gossip information. It could be that the strong tendency to trust negative information (negativity bias) overrode the trust in firsthand or gossip information. Another possibility for the conflicting results might be that the neutral puppet was considered to be a stranger by the five-year-olds whom they avoided. However, this is not what we see in our results. Five-year-olds chose the neutral puppet more often than the target puppet. The seven-year-olds might have been aware of the manipulative potential of gossip and thus selectively trusted their own observations. In support of this possibility, four seven-year-old-children spontaneously claimed that the gossiper was lying when the gossip information was at odds with their own observation. There were no five-year-old children who drew this conclusion. Possibly, seven-year-olds have a more sophisticated understanding of the relative value of firsthand versus gossip information than did the young preschoolers in Jaswal (2010). Finally, in Jaswal's study (2010), children received testimony from an adult, an authority figure. In the present study, on the other hand, we used puppets as gossipers, thereby attempting to avoid an authority bias.

Our finding that five-year-old children selectively relied on negative information is consistent with previous work on the "negativity bias" (e.g., Koenig \& Doebel, 2013; Peeters \& Czapinski, 1990; Rozin \& Royzman, 2001; Vaish, Grossmann, \& Woodward, 2008). A range of studies have shown that younger children especially pay selective attention to negative over positive information (see Koenig \& Doebel, 2013; Peeters \& Czapinski, 1990; Rozin \& Royzman, 2001; Vaish et al., 2008). Vaish and colleagues (2008) argued that by the age of twelve months, infants display a strong negativity bias. Also in the social domain, it might be an adaptive strategy to rely selectively on negative information in order to avoid exploitation by social partners. In our study, five-year-old children, but not seven-year-old children, trusted negative information significantly more than positive information. Such selective reliance on negative information might diminish over the course of development (Koenig \& Doebel, 2013), allowing children to pay attention to more subtle factors, such as the source of information.

This study provides an important first step in documenting children's trust regarding others' gossip in general, and their reliance on different sources of social information in particular. However, it also has some limitations. First, because we wanted to keep the gossip and observation videos as similar as possible, we had a puppet act as gossiper. Experimental designs involving a peer and even an adult gossiper should be used to investigate the extent to which the current findings generalize to other situations. Having an adult gossiper might help clarify why the current results differ from previous work. Furthermore, in the present study, the gossip messages indicated that the puppet "always" helps or destroys "everything." Future research should study the influence of such generic statements on children's trust and explore the conditions under which children rely on gossip (Sperber et al., 2010).

\section{ACKNOWLEDGMENTS}

We thank Katharina Haberl and the child lab team at the Max Planck Institute. Special thanks go to Jana Jurkat for her relevant help during every stage of this work. Furthermore we thank all student assistants and interns for their help in the day care centers. Finally, we thank Anne Sibilsky and Diotima Rapp for reliability coding.

\section{REFERENCES}

Baumeister, R., Zhang, L., \& Vohs, K. (2004). Gossip as cultural learning. Review of General Psychology, 8, 111. doi: 10.1037/1089-2680.8.2.111

Corriveau, K., Fusaro, M., \& Harris, P. (2009). Going with the flow preschoolers prefer nondissenters as informants. Psychological Science, 20, 372-377. doi: 10.1111/j.1467-9280.2009.02291.x

Corriveau, K., \& Harris, P. (2009). Choosing your informant: Weighing familiarity and recent accuracy. Developmental Science, 12, 426-437. doi: 10.1111/j.1467-7687.2008.00792.x

Corriveau, K. H., \& Harris, P. L. (2010). Preschoolers (sometimes) defer to the majority in making simple perceptual judgments. Developmental Psychology, 46, 437. doi: 10.1037/a0017553

Dobson, A. J. (2008). An introduction to generalized linear models. Boca Raton, FL: CRC Press.

Dunbar, R. (2004). Gossip in evolutionary perspective. Review of General Psychology, 8, 100. doi: 10.1037/10892680.8.2.100 
Engelmann, J. M., Herrmann, E., \& Tomasello, M. (2016). Preschoolers affect others' reputations through prosocial gossip. British Journal of Developmental Psychology, 34, 447-460. doi: 10.1111/bjdp.12143

Feinberg, M., Willer, R., Stellar, J., \& Keltner, D. (2012). The virtues of gossip: Reputational information sharing as prosocial behavior. Journal of Personality and Social Psychology, 102, 1015. doi: 10.1037/a0026650

Fine, G. A. (1977). Social components of children's gossip. Journal of Communication, 27, 181-185. doi: 10.1111/j.14602466.1977.tb01815.x

Forstmeier, W., \& Schielzeth, H. (2011). Cryptic multiple hypotheses testing in linear models: Overestimated effect sizes and the winner's curse. Behavioral Ecology and Sociobiology, 65, 47-55. doi: 10.1007/s00265-010-1038-5

Harris, P. (2012). Trusting what you're told: How children learn from others. Cambridge, MA: Belknap Press of Harvard University Press. doi: 10.4159/harvard.9780674065192

Herrmann, E., Keupp, S., Hare, B., Vaish, A., \& Tomasello, M. (2013). Direct and indirect reputation formation in nonhuman great apes (Pan paniscus, Pan troglodytes, Gorilla gorilla, Pongo pygmaeus) and human children (Homo sapiens). Journal of Comparative Psychology, 127, 63. doi: 10.1037/a0028929

Ingram, G. P. (2014). From hitting to tattling to gossip: An evolutionary rationale for the development of indirect aggression. Evolutionary Psychology, 12, 343-363. doi: 10.1177/147470491401200205

Ingram, G. P., \& Bering, J. M. (2010). Children's tattling: The reporting of everyday norm violations in preschool settings. Child Development, 81, 945-957. doi: 10.1111/j.1467-8624.2010.01444.x

Jaswal, V. K. (2010). Believing what you're told: Young children's trust in unexpected testimony about the physical world. Cognitive Psychology, 61, 248-272. doi: 10.1016/j.cogpsych.2010.06.002

Koenig, M. A., Clément, F., \& Harris, P. L. (2004). Trust in testimony: Children's use of true and false statements. Psychological Science, 15, 694-698. doi: 10.1111/j.0956-7976.2004.00742.x

Koenig, M. A., \& Doebel, S. (2013). Children's understanding of unreliability. In M. Banaji \& S. Gelman (Eds.), Navigating the social world: What infants, children, and other species can teach us (pp. 235-240). Oxford: University Press.

La Greca, A. M., Parker, J. G., \& Kuttler, A. F. (2002). Developmental and gender differences in preadolescents' judgments of the veracity of gossip. Merrill-Palmer Quarterly, 48, 105-132. doi: 10.1353/mpq.2002.0008

Mascaro, O., \& Sperber, D. (2009). The moral, epistemic, and mindreading components of children's vigilance towards deception. Cognition, 112, 367-380. doi: 10.1016/j.cognition.2009.05.012

McCullagh, P., \& Nelder, J. A. (2008). Generalized linear models. London: Chapman and Hall.

Nowak, M. A., \& Sigmund, K. (2005). Evolution of indirect reciprocity. Nature, 437, 1291-1298. doi: 10.1038/ nature04131

Pasquini, E., Corriveau, K., Koenig, M., \& Harris, P. (2007). Preschoolers monitor the relative accuracy of informants. Developmental Psychology, 43, 1216. doi: 10.1037/0012-1649.43.5.1216

Peeters, G., \& Czapinski, J. (1990). Positive-negative asymmetry in evaluations: The distinction between affective and informational negativity effects. European Review of Social Psychology, 1, 33-60. doi: 10.1080/14792779108401856

Rozin, P., \& Royzman, E. B. (2001). Negativity bias, negativity dominance, and contagion. Personality and Social Psychology Review, 5, 296-320. doi: 10.1207/S15327957PSPR0504_2

Sommerfeld, R., Krambeck, H., Semmann, D., \& Milinski, M. (2007). Gossip as an alternative for direct observation in games of indirect reciprocity. Proceedings of the National Academy of Sciences of the United States of America, 104, 17435-17440. doi: 10.1073/pnas.0704598104

Sperber, D., \& Baumard, N. (2012). Moral reputation: An evolutionary and cognitive perspective. Mind Language, 27, 495518. doi: 10.1111/mila.12000

Sperber, D., Clément, F., Heintz, C., Mascaro, O., Mercier, H., Origgi, G., \& Wilson, D. (2010). Epistemic vigilance. Mind \& Language, 25, 359-393. doi: 10.1111/j.1468-0017.2010.01394.x

Vaish, A., Grossmann, T., \& Woodward, A. (2008). Not all emotions are created equal: The negativity bias in socialemotional development. Psychological Bulletin, 134, 383. doi: 10.1037/0033-2909.134.3.383

Wedekind, C., \& Milinski, M. (2000). Cooperation through image scoring in humans. Science, 288, 850-852. doi: 10.1126/ science. 288.5467 .850 